\title{
Mixed Somatotroph and Lactotroph Adenoma
}

National Cancer Institute

\section{Source}

National Cancer Institute. Mixed Somatotroph and Lactotroph Adenoma. NCI Thesaurus.

Code C45927.

An infrequent pituitary gland adenoma composed of an admixture of acidophilic and chromophobic cells that produce growth hormone and prolactin respectively. Unlike mammosomatotroph adenomas, these two hormones are not localized in the same cell by immunohistochemistry. 